\title{
Symptom burden in community-dwelling older people with multimorbidity: a cross-sectional study
}

Jeanette Eckerblad ${ }^{1 *}$, Kersti Theander ${ }^{2}$, Anne Ekdahl ${ }^{3,4}$, Mitra Unosson ${ }^{1}$, Ann-Britt Wirehn ${ }^{5}$, Anna Milberg ${ }^{1,6,7}$, Barbro Krevers ${ }^{8}$ and Tiny Jaarsma ${ }^{1}$

\begin{abstract}
Background: Globally, the population is ageing and lives with several chronic diseases for decades. A high symptom burden is associated with a high use of healthcare, admissions to nursing homes, and reduced quality of life. The aims of this study were to describe the multidimensional symptom profile and symptom burden in community-dwelling older people with multimorbidity, and to describe factors related to symptom burden.

Methods: A cross-sectional study including 378 community-dwelling people $\geq 75$ years, who had been hospitalized $\geq 3$ times during the previous year, had $\geq 3$ diagnoses in their medical records. The Memorial Symptom Assessment Scale was used to assess the prevalence, frequency, severity, distress and symptom burden of 31 symptoms. A multiple linear regression was performed to identify factors related to total symptom burden.

Results: The mean number of symptoms per participant was 8.5 (4.6), and the mean total symptom burden score was 0.62 (0.41). Pain was the symptom with the highest prevalence, frequency, severity and distress. Half of the study group reported the prevalence of lack of energy and a dry mouth. Poor vision, likelihood of depression, and diagnoses of the digestive system were independently related to the total symptom burden score.

Conclusion: The older community-dwelling people with multimorbidity in this study suffered from a high symptom burden with a high prevalence of pain. Persons with poor vision, likelihood of depression, and diseases of the digestive system are at risk of a higher total symptom burden and might need age-specific standardized guidelines for appropriate management.
\end{abstract}

Keywords: Chronic disease, Older people, Symptom assessment

\section{Background}

Chronic conditions among older people represent some of the largest health care challenges of this century, and one which will affect both the socioeconomics and the health care system [1]. Globally, the population is ageing and people can now live with several chronic diseases for decades [2]. Chronic diseases tend to increase with old age. An international systematic review reported that approximately $62 \%$ of all the people aged between $65-74$ years, and $81.5 \%$ of people above 85 years suffer from multiple chronic diseases [3]. A co-occurrence of $\geq 2$

\footnotetext{
* Correspondence: jeanette.eckerblad@liu.se

'Department of Social and Welfare Studies, Linkoping University, Linkoping, Sweden

Full list of author information is available at the end of the article
}

diseases, where at least one is chronic, is defined as multimorbidity [4]. Multimorbidity is a condition with a high impact on functional impairment and quality of life $[5,6]$, and is a condition that often results in a variety of different symptoms [7].

In a number of studies, older people have been reported to suffer from various symptoms. These reports have been based on measurements of a single symptom such as depression [8] fatigue [9], sleep disorder [10] or pain [11]. Other studies have been based on only one symptom dimension, usually intensity or severity $[12,13]$. The use of a multidimensional approach with the aforementioned dimensions is advocated both in research [14] and clinical practice [15]. A multidimensional assessment may also serve as a sufficient patient-reported outcome and it has 
been shown to be a sensitive tool to measure the effectiveness of interventions [16]. Symptom burden is a complex concept that goes beyond the scoring of any symptom instrument. To persons suffering from an advanced disease the impact of symptoms is often a well-known [17]. In an older population, high symptom burden is associated with increased health care utilization, frequent visits to the emergency department, hospitalization [18], admissions to nursing homes [19], and reduced quality of life $[20,21]$. Symptom burden has been defined in different ways. In this study symptom burden is defined as "the subjective, quantifiable prevalence, frequency, and severity of symptoms placing a physiological burden on patients and producing multiple negative, physical, and emotional patient responses" [22].

Earlier studies within the research field of multidimensional symptoms have usually been conducted on specific chronic diseases, for example chronic obstructive pulmonary disease (COPD), heart failure (HF) or renal disease $[20,21,23]$, and there is a paucity of studies focusing on multidimensional symptoms in older persons with multimorbidity. Existing guidelines for disease management are disease-specific, and they are not designed for people with multimorbidity [24]. If we set out to reduce the impact of diseases by reducing the symptom frequency, minimizing symptom severity, and relieving symptom distress it is essential to look at and assess the total symptom burden, not just one disease at the time.

\section{Aims}

The aims of this study were to describe the multidimensional symptom profile and symptom burden of community-dwelling older people with multimorbidity. An additional aim was to describe which factors are related to symptom burden.

\section{Methods \\ Design}

This is a cross-sectional study using baseline data from a randomized controlled trial intended to include community-dwelling older people with multimorbidity and who had a great need for health care during the preceding year [25].

\section{Participants}

Participants were recruited from one municipality through the patient administrative system of the County Council. Norrkoping is a middle-sized city, (120 000) in the southeast of Sweden, where approximately $9 \%$ of the inhabitants are $\geq 75$ years. Inclusion criteria were: people $\geq$ 75 years, who had been hospitalized $\geq 3$ times during the previous year, who had $\geq 3$ diagnoses in their medical records according to the International classification of diseases (ICD-10) [18] and who lived at home. The only exclusion criterion was if participants were already living in a nursing home. Eight hundred forty-four older people were invited to participate; of those, 79 were excluded since they had moved to a nursing home just before the study started, 26 were deceased, 32 could not be reached, and 304 declined to participate. Out of the 403 that were willing to participate, in 22 cases written informed consent was missing and they were therefore excluded. In the present study, only those who had completed the symptom assessment instrument were included; in total 378 eligible participants. The flow-chart of the study is visualized in Figure 1.

\section{Procedures}

An invitation letter explaining the purpose of the study was sent to the eligible older people. They were then contacted by telephone, and those who gave oral informed consent were scheduled for an appointment at their home for protocolled directed interviews during which

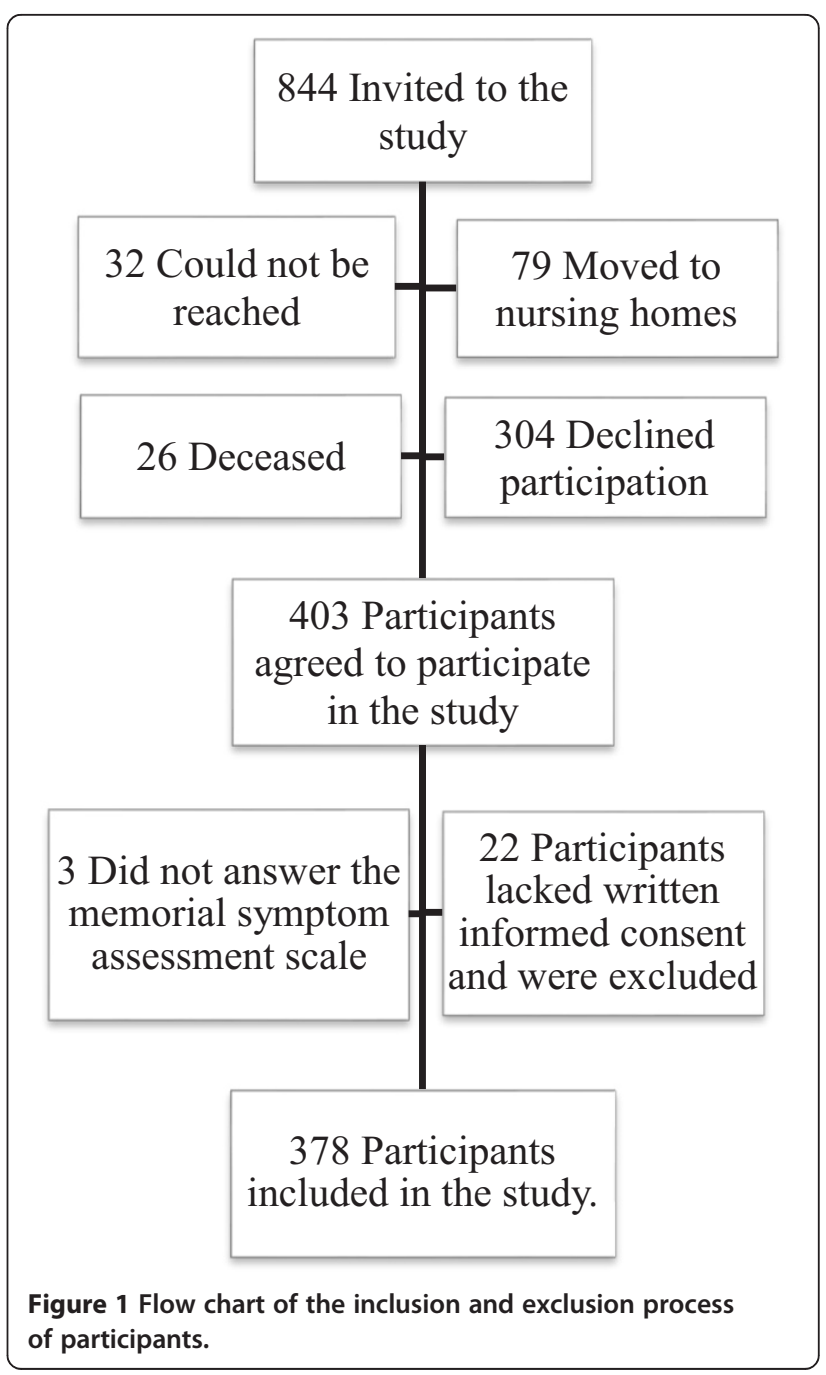


written consent was obtained. All data were collected with protocol-guided interviews, performed by specially trained registered nurses or occupational therapists between February 2011 and December 2011. The study followed the ethical guidelines given in the declaration of Helsinki and was approved by the regional ethical review board in Linkoping (Dnr. 2011/41-31).

\section{Assessments}

\section{Symptoms}

Symptom prevalence, symptom experience and symptom burden were assessed using the Memorial Symptom Assessment Scale (MSAS) [15]. MSAS includes a large number of commonly occurring symptoms and assesses the prevalence of 32 symptoms. It considers symptoms experienced during the preceding week in terms of three dimensions - frequency, severity and distress - for 24 symptoms, and two dimensions - severity and distress for eight symptoms. The format for responses is as follows. The prevalence of each symptom is answered by yes/no: frequency on a four-point scale - rarely, occasionally, frequently or almost constantly; severity on a four-point scale - slight, moderate, severe, or very severe; and distress on a five-point scale - not at all, a little bit, somewhat, quite a bit or very much [26]. For clarity of reporting, we used the terms 'high frequency', 'high severity' and 'high distress' for the two highest scores of each symptom dimension. One item dealing with sexual interest or activity was excluded from the original instrument prior to the data collection. The data collector did not feel comfortable asking the old and often lonely people a question about sex. This left the instrument with 31 symptoms. The coding of the instrument was based upon the instruction of the original authors [26]. The symptom burden score was calculated as a mean score of frequency, severity and distress of each symptom [15]. The total symptom burden score per patient (TMSAS) is the mean of all 31 symptom burden scores [26]. The MSAS was originally conducted to assess symptoms in people with cancer [26] but has since been tested and evaluated on people with different chronic diseases [20,21,27]. The MSAS is validated and has been used in a Swedish context $[28,29]$. The Cronbach's alpha coefficient for TMSAS in this study was 0.82 .

\section{Background characteristics}

Background data collected in this study included age, gender, current marital status, living situation, next of kin, education level, use of tobacco and alcohol, problems with vision, hearing, and body mass index (BMI). Cognitive decline was measured by the Mini-Mental State Examination (MMSE), which is a validated 30-point brief questionnaire test that is used to screen for cognitive impairment. In this test, 24 points or more is considered as normal cognitive function, $18-23$ is mild-moderate cognitive dysfunction, and $<18$ indicates severe cognitive dysfunction. The likelihood of depression was assessed by using the Geriatric Depression Scale (GDS-15) [30], which is a validated self-reported instrument. Data on the participants' medical diagnoses were provided by the 'Data Care Warehouse', which is a population-based, administrative database run by the County Council.

\section{Statistical analysis}

The statistical analysis is described by frequencies and percentages for categorical variables, and continuous data by means and standard deviations (SD) for normally distributed data. To be able to compare results from this study with previous research, MSAS symptom burden scores are presented as mean (SD) even though the variables were often skewed. A multiple linear regression analysis was performed to determine independent associations between TMSAS and the background characteristics from Table 1 . The multiple model was built by entering those variables that had univariate statistical significance with a $\mathrm{p}<0.05$ in the correlation, retaining those variables with $\mathrm{p}<0.05$ in the final regression model. All two-way interactions were tested in the model. Data were analyzed using PASW Statistical (SPSS) version 20. The significance level was set at $\mathrm{p} \leq 0.05$.

\section{Results}

The mean age of the participants was 82 (4.8) years, with an almost equal distribution of men (52\%) and women (48\%) (Table 1). Significant differences were found both regarding gender and age between people who agreed to participate $(\mathrm{n}=381)$ and those who declined, could not be reached, had moved to nursing home, did not provide informed consent or had recently died $(n=461)$. People who agreed to participate were slightly younger than the non-participants $82(4.8)$ vs.83 $(5.4)$ years $(\mathrm{p}=0.024)$ and more men than women accepted the invitation to participate $(\mathrm{p}=0.039)$.

In total, $51 \%$ of participants lived alone and $81 \%$ had an educational level consisting of elementary school. Approximately one-third (28\%) reported problems with vision, with or without glasses and (34\%) reported problems with hearing, with or without hearing device. In total, $8 \%$ currently smoked and $7 \%$ drank alcohol on a daily basis. The mean score on the MMSE was 26 (3.2), and $20 \%$ of the participants had a score below 24 that could indicate cognitive dysfunction. With regard to depression we found that $32 \%$ scored equal or higher than 5 on the GDS, indicating the likelihood of depression (Table 1).

Participants in this study had three or more medical diagnoses in their medical record. Almost all participants (96\%) had at least one disease listed in ICD chapter 9, diseases of the circulatory system. Participants also had 
Table 1 Background characteristics

\begin{tabular}{|c|c|}
\hline & $\mathrm{N}=378$ \\
\hline Age (yrs.), mean (SD) & $82(4.8)$ \\
\hline Women n (\%) & $182(48)$ \\
\hline Lived alone $\mathrm{n}(\%)$ & $193(51)$ \\
\hline Elementary school n (\%) & $305(81)$ \\
\hline Secondary school or higher education n (\%) & $68(18)$ \\
\hline $\begin{array}{l}\text { Poor hearing with or without } \\
\text { hearing device. } n(\%)\end{array}$ & $130(34)$ \\
\hline Poor vision with or without glasses. n (\%) & $104(28)$ \\
\hline Smokers n (\%) & $32(8)$ \\
\hline Alcohol on daily basis. $n(\%)$ & $27(7)$ \\
\hline BMI $\left(\mathrm{kg} / \mathrm{m}^{2}\right)$ mean $(\mathrm{SD})$ & $26.1(4.6)$ \\
\hline Underweight (BMI < 18.5) n (\%) & $8(2)$ \\
\hline Normal (BMI $18.5 \leq 24.9)$ n (\%) & $145(38)$ \\
\hline Overweight (BMI $25 \leq 29.9$ ) n (\%) & $140(37)$ \\
\hline Obese (BMI > 30) n (\%) & $60(16)$ \\
\hline MMSE mean (SD) & $26.3(3.2)$ \\
\hline MMSE 20-24 n (\%) & $65(17)$ \\
\hline MMSE 10-19n (\%) & $12(3)$ \\
\hline MMSE $\leq 9 n(\%)$ & 0 \\
\hline GDS mean (SD) & $3.7(3.0)$ \\
\hline GDS $\geq 5$ n (\%) & $120(32)$ \\
\hline \multicolumn{2}{|l|}{ Diagnosis according to ICD 10 Chapter } \\
\hline $\begin{array}{l}\text { 01. Certain infectious and parasitic diseases } \\
\text { (A00-B99) } \mathrm{n}(\%)\end{array}$ & $166(44)$ \\
\hline 02. Neoplasma (C00-D48) n (\%) & $158(42)$ \\
\hline $\begin{array}{l}\text { 03. Diseases of the blood and blood-forming } \\
\text { organs and certain disorders involving the } \\
\text { immune mechanism (D50-D89) n (\%) }\end{array}$ & $116(31)$ \\
\hline $\begin{array}{l}\text { 04. Endocrine, nutritional and metabolic } \\
\text { diseases (E00-E90) } n(\%)\end{array}$ & $187(50)$ \\
\hline $\begin{array}{l}\text { 05. Mental and behavioral disorders } \\
\text { (F00-F99) n (\%) }\end{array}$ & $127(33)$ \\
\hline $\begin{array}{l}\text { 06. Diseases of the nervous system } \\
\text { (G00-G99) } \mathrm{n}(\%)\end{array}$ & $130(34)$ \\
\hline $\begin{array}{l}\text { 07. Diseases of the eye and adnexa } \\
(\mathrm{H} 00-\mathrm{H} 59) \mathrm{n}(\%)\end{array}$ & $219(58)$ \\
\hline $\begin{array}{l}\text { 08. Diseases of the ear and mastoid process } \\
(\mathrm{H} 60-\mathrm{H} 95) \mathrm{n}(\%)\end{array}$ & $142(37)$ \\
\hline $\begin{array}{l}\text { 09. Diseases of the circulatory system } \\
(100-199) n(\%)\end{array}$ & $362(96)$ \\
\hline $\begin{array}{l}\text { 10. Diseases of the respiratory system } \\
(J 00-J 99) n(\%)\end{array}$ & $210(55)$ \\
\hline $\begin{array}{l}\text { 11. Diseases of the digestive system } \\
(\text { K00-K93) } n(\%)\end{array}$ & $206(54)$ \\
\hline $\begin{array}{l}\text { 12. Diseases of the skin and subcutaneous } \\
\text { tissue (L00-L99) n (\%) }\end{array}$ & $164(43)$ \\
\hline $\begin{array}{l}\text { 13. Diseases of the musculoskeletal system } \\
\text { and connective tissue (M00-M99) n (\%) }\end{array}$ & $295(78)$ \\
\hline
\end{tabular}

Abbreviations: BMI Body Mass Index, MMSE Mini-Mental State Examination, GDS-15 Geriatric Depression Scale, ICD International Classification of Diseases. diseases from ICD chapter 9 relating to the musculoskeletal system (83\%), diseases of the digestive system $(60 \%)$ and diseases of the eye and adnexa (58\%) (Table 1).

\section{Symptom prevalence}

The mean number of symptoms per patient (total prevalence) was 8.5 (4.6), 30\% of the participants reported 10 co-occurring symptoms or more, and three participants $(0.8 \%)$ reported no symptoms at all. In the total group of respondents, pain was the symptom with the highest prevalence $(67 \%)$. Half of the participants $(47-51 \%)$ reported dry mouth, lack of energy, numbness and tingling in the hands and feet. Almost four out of ten (36-42\%) experienced problems with feeling drowsy, dizziness, shortness of breath, difficulty sleeping, feeling sad, and worrying (Table 2).

\section{Symptom experience}

Pain was the symptom reported with the highest frequency score, with four out of 10 participants (43\%) reporting that the symptom had occurred frequently or almost constantly during the preceding week. Nausea and vomiting were reported by less than $5 \%$ (Table 2).

Pain was a symptom that most participants reported as severe. One-third (31\%) of the participants gave the symptom a high severity score (severe or very severe). Difficulty sleeping and lack of energy were reported by $17-21 \%$ respectively as being "severe or very severe." (Table 2).

Pain and a lack of energy were reported with a high symptom distress score (quite a bit or very much distress) by $35 \%$ and $25 \%$ of the respondents respectively. Numbness and tingling in the hands and feet, dizziness, shortness of breath and difficulty sleeping were reported by $14-16 \%$ of the participants as causing high symptom distress (Table 2).

Symptom burden is reported for participants who experienced the symptoms during the preceding week and not for the total group of 378 participants. For 29 of 31 assessed symptoms, patients who reported the respective symptom had a mean score of $\geq 2.0$, and seven symptoms were reported to have a mean symptom burden of more than 2.6 (Table 3). Pain had the highest symptom burden score; the 248 patients who reported having pain had a mean symptom burden of $2.8(0.68)$. With regard to pain we found that $45 \%$ of the 248 participants who reported pain had a symptom burden score of $\geq 3.0$ (Table 3).

\section{Factors related to symptom burden}

For the total group of participants the total symptom burden (TMSAS) had a mean (SD) score of $0.62(0.41)$. TMSAS was significantly correlated with sex $\left(\mathrm{r}_{\mathrm{s}}=-0.16\right)$, with women reporting a higher score than men. TMSAS 
Table 2 Symptom prevalence and symptom experience in older people with multi-morbidity

\begin{tabular}{|c|c|c|c|c|}
\hline \multirow[b]{2}{*}{ Symptoms } & \multirow[b]{2}{*}{ Prevalence $n /(\%)$} & \multicolumn{3}{|c|}{ Symptom experience } \\
\hline & & High frequency $n /(\%)^{a}$ & High severity. $\mathrm{n} /(\%)^{\mathrm{b}}$ & High distress $n /(\%)^{c}$ \\
\hline \multicolumn{5}{|l|}{ N 378 (\%) } \\
\hline Pain & $253(67)$ & $164(43)$ & $117(31)$ & $132(35)$ \\
\hline Dry mouth & $193(51)$ & $103(27)$ & $55(15)$ & $49(13)$ \\
\hline Lack of energy & $189(50)$ & $122(32)$ & $81(21)$ & $94(25)$ \\
\hline Numbness/tingling in hands/feet & $178(47)$ & $95(25)$ & $57(15)$ & $57(15)$ \\
\hline Feeling drowsy & $158(42)$ & $52(14)$ & $34(9)$ & $38(10)$ \\
\hline Dizziness & $156(41)$ & $65(17)$ & $59(16)$ & $61(16)$ \\
\hline Difficulty sleeping & $153(40)$ & $92(24)$ & $64(17)$ & $56(15)$ \\
\hline Shortness of breath & 149 (39) & $68(18)$ & $59(16)$ & $55(15)$ \\
\hline Feeling sad & $138(36)$ & $46(12)$ & $54(14)$ & $48(13)$ \\
\hline Worrying & $136(36)$ & $38(10)$ & $45(12)$ & $39(10)$ \\
\hline Swelling of arms or legs & $130(35)$ & N/A & $32(8)$ & $30(8)$ \\
\hline Cough & $129(34)$ & $43(11)$ & $31(8)$ & $34(9)$ \\
\hline Itching & $118(31)$ & $48(13)$ & $38(10)$ & $32(8)$ \\
\hline Problems with urination & $104(28)$ & $71(19)$ & $43(11)$ & $44(12)$ \\
\hline Feeling nervous & $103(27)$ & $36(10)$ & $28(7)$ & $31(8)$ \\
\hline Changes in skin & $102(27)$ & N/A & $13(3)$ & $18(5)$ \\
\hline Feeling bloated & $92(24)$ & $45(12)$ & $37(10)$ & $34(9)$ \\
\hline Feeling irritable & $85(23)$ & $25(7)$ & $21(6)$ & $18(5)$ \\
\hline Constipation & $79(21)$ & N/A & $33(9)$ & $30(8)$ \\
\hline Difficulty concentrating & $74(20)$ & $21(6)$ & $23(6)$ & $25(7)$ \\
\hline Sweating & $71(19)$ & $26(7)$ & $19(5)$ & $19(5)$ \\
\hline Lack of appetite & $69(18)$ & $43(11)$ & $22(6)$ & $17(4)$ \\
\hline Diarrhea & $60(16)$ & $22(6)$ & $34(9)$ & $30(8)$ \\
\hline Difficulty swallowing & $54(14)$ & $31(8)$ & $25(7)$ & $24(6)$ \\
\hline Nausea & $52(14)$ & $14(4)$ & $17(5)$ & $17(5)$ \\
\hline Change in the way food tastes & $43(11)$ & N/A & $10(3)$ & $8(2)$ \\
\hline Mouth sores & $42(11)$ & N/A & $14(4)$ & $14(4)$ \\
\hline Weight loss & $28(7)$ & N/A & $7(2)$ & $7(2)$ \\
\hline "I don't look like myself" & $23(6)$ & N/A & $10(3)$ & $11(3)$ \\
\hline Hair loss & $19(5)$ & N/A & $6(2)$ & $6(2)$ \\
\hline Vomiting & $14(4)$ & $1(0,3)$ & $5(1)$ & $5(1)$ \\
\hline
\end{tabular}

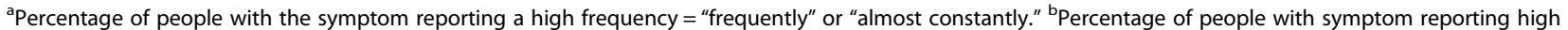
severity = "severe" or "very severe." "Percentage of people with the symptom reporting a high distress "quite a bit" or "very much." N/A = Not Applicable.

was also significantly correlated vision $\left(r_{s}=-0.14\right)$ and hearing $\left(r_{s}=-0.10\right)$, with participants with poor vision or hearing reporting higher TMSAS scores. TMSAS was correlated with risk of depression $\left(r_{s}=0.57\right)$, diseases of mental and behavioral disorder $\left(r_{s}=0.21\right)$, diseases of the digestive system $\left(r_{s}=0.16\right)$ and diseases of the nervous system $\left(r_{s}=0.11\right)$. In the multiple linear regression, TMSAS was independently related to poor vision (beta $=-0.153)$, risk of depression (beta $=0.566$ ), and diseases of the digestive system (beta $=0.109$ ). The $R^{2}$ for this model was 0.38 , indicating that $38 \%$ of the variance of
TMSAS could be explained by these three predictors (Table 4).

\section{Discussion}

There is a lack of knowledge concerning the multidimensional symptom profile and symptom burden in older people with multimorbidity. An important finding of this study was that older community-dwelling people with multimorbidity suffer a considerable symptom burden, with a mean of eight symptoms per person, and some people even reporting 10 symptoms. Almost seven 
Table 3 MSAS symptom burden score of older people who reported the symptom as present during the previous week

\begin{tabular}{|c|c|c|c|}
\hline Symptom & $\begin{array}{l}\text { Number of patients } \\
\text { who reported } \\
\text { the symptom }\end{array}$ & $\begin{array}{l}\text { Symptom } \\
\text { burden score }\end{array}$ & (SD) \\
\hline Pain & 248 & 2.8 & $(0.68)$ \\
\hline Lack of energy & 191 & 2.7 & $(0.67)$ \\
\hline Difficulty swallowing & 53 & 2.7 & $(0.73)$ \\
\hline "I don't look like myself" & 22 & 2.7 & $(1.03)$ \\
\hline Difficulty sleeping & 152 & 2.6 & $(0.70)$ \\
\hline Problems with urination & 103 & 2.6 & $(0.76)$ \\
\hline Diarrhea & 59 & 2.6 & $(0.78)$ \\
\hline $\begin{array}{l}\text { Numbness/tingling } \\
\text { in hands/feet }\end{array}$ & 175 & 2.5 & $(0.74)$ \\
\hline Shortness of breath & 146 & 2.5 & $(0.67)$ \\
\hline Feeling sad & 135 & 2.5 & $(0.72)$ \\
\hline Feeling bloated & 90 & 2.5 & $(0.65)$ \\
\hline Constipation & 79 & 2.5 & $(0.72)$ \\
\hline Dry mouth & 189 & 2.4 & $(0.74)$ \\
\hline Dizziness & 151 & 2.4 & $(0.79)$ \\
\hline Worrying & 135 & 2.4 & $(0.64)$ \\
\hline Feeling nervous & 102 & 2.4 & $(0.72)$ \\
\hline Difficulty concentrating & 75 & 2.4 & $(0.67)$ \\
\hline Lack of appetite & 67 & 2.4 & $(0.67)$ \\
\hline Itching & 114 & 2.3 & $(0.76)$ \\
\hline Sweating & 67 & 2.3 & $(0.80)$ \\
\hline Mouth sores & 41 & 2.3 & $(0.87)$ \\
\hline Feeling drowsy & 151 & 2.2 & $(0.66)$ \\
\hline Cough & 125 & 2.2 & $(0.66)$ \\
\hline Nausea & 51 & 2.2 & $(0.62)$ \\
\hline Hair loss & 19 & 2.2 & (0.91) \\
\hline Vomiting & 14 & 2.2 & $(0.32)$ \\
\hline Swelling of arms or legs & 126 & 2.1 & $(0.80)$ \\
\hline Feeling irritable & 82 & 2.1 & $(0.72)$ \\
\hline $\begin{array}{l}\text { Change in the way } \\
\text { food tastes }\end{array}$ & 41 & 2.1 & $(0.76)$ \\
\hline Weight loss & 24 & 1.9 & $(0.97)$ \\
\hline Changes in skin & 97 & 1.8 & $(0.72)$ \\
\hline
\end{tabular}

The MSAS symptom burden score is the mean score of the three dimensions: frequency, severity and distress.

out of ten older people suffered from pain. Pain was also the symptom with the highest frequency, severity, and distress and had the highest symptom burden score of all 31 symptoms. Three factors were found to be independently associated with total symptom burden: poor vision, likelihood of depression, and diseases of the digestive system.
Table 4 Dependent Variable TMSAS N = 378

\begin{tabular}{llll}
\hline Independent variables & Unstandardized $\boldsymbol{\beta}$ & $\begin{array}{l}\text { Standardized } \\
\text { beta }\end{array}$ & P level \\
\hline Poor vision & -0.140 & -0.153 & $<0.001$ \\
$\begin{array}{l}\text { Likelihood of } \\
\text { depression }\end{array}$ & 0.077 & 0.566 & $<0.001$ \\
$\begin{array}{l}\text { Diseases of the } \\
\text { digestive system }\end{array}$ & 0.090 & 0.109 & 0.008 \\
\hline
\end{tabular}

Multiple linear regression analysis of the dependent TMSAS and the independent poor vision, likelihood of depression, diseases of the digestive system in 378 older people with multimorbidity.

$\mathrm{R}$ square $0.38 \mathrm{P}<0.05$.

Abbreviation: TMSAS Total Memorial symptom assessment scale.

Poor vision = self-reported, Likelihood of depression = Geriatric Depression Scale $\geq 5$, Diseases of the digestive system = participants with ICD (K00-K93) in their medical record.

Almost seven out of 10 participants in this study had experienced pain during the preceding week, which is a high number but in line with some other studies in which community-dwelling older people reported a pain prevalence of between 20 to $79 \%$ [31,32]. As reflected by the high symptom burden, our findings show that pain causes older people a considerable amount of suffering. This group of older people living in a home had a burden of pain that was comparable to the scores of hospitalized cancer patients near the end of life [27], which was not something we had expected. Earlier studies described pain as underdiagnosed and undertreated [31,33] and found that, irrespective of clinical diagnosis, $25 \%$ of older people do not receive analgesic treatment for pain, and people older than 85 are even less likely to receive it [33]. At the same time, polypharmacy is a huge problem within the group of older people with multimorbidity; inappropriate drug intake causes complications and symptoms, leading to repeated visits to the emergency department and hospitalization [34]. There has been a lack of age-specific standardized management guidelines for geriatric pain, and health professionals have felt that multimorbidity complicates appropriate management [35]. Just recently, new guidance for treating pain in the elderly was published [31].

In addition to pain, lack of energy, difficulty swallowing, "I don't look like myself", difficulty sleeping, problems with urination, and diarrhea had a high symptom burden in those who experienced them. These symptoms seem rather non-specific, that is, not related to one specific medical diagnosis, and are not always recognized as being important. However, earlier studies have shown that older people with a high symptom burden have a poorer quality of life and higher use of health services $[18,19]$. To facilitate and improve symptom management, health care providers should not only look at and assess disease-specific symptoms but also take general symptoms into consideration. 
We also found that poor vision, likelihood of depression, and diseases of the digestive system were associated with total symptom burden. It is known that people in a depressive mood experience a higher symptom burden than those who are not [36]. Earlier studies have confirmed the association between depression and pain [37]. If recognized and treated, depression is often reversible, but if left untreated, depression may result in the onset of physical, cognitive, functional, and social impairment, as well as decreased quality of life, [38] and higher mortality [39]. The independent relationship between poor vision and the total symptom burden scale has not previously been described, but other studies have reported that people with poor hearing or vision are more likely to experience disability, and that there are associations between poor vision, poor hearing and depression [40]. Earlier studies have shown that people with diseases of the digestive system have a lower health-related quality of life $[41,42]$ and that the severity of the gastrointestinal symptoms and health-related quality of life are associated [41]. Reflecting on the high symptom burden in multimorbid older people, we observe that in our current health care system most care is organized from a single disease perspective, an arrangement into which older people with multimorbidity do not quite seem to fit [6]. These older people have reported feeling unwelcome or even like a burden when they need to seek care [43]. However, health care providers still have the responsibility to give patients optimal support to restore or at least achieve an acceptable level of symptom relief [44]. A routine of a broad assessment of symptoms and symptom burden (not restricted to the disease-specific burden) might lead to better symptom management $[19,45]$ which could maintain independence and functional ability, and sustain or improve quality of life for older people with multimorbidity.

\section{Strengths and limitations}

The strength of this study is that all data are assessed by protocol-guided interviews, leaving us with little missing data. However, there is still a risk that the older people's symptom experience or burden have been underestimated since studies have shown that when questionnaires are self-administered instead of interviewer-administered the scores tend to be higher, so this should be taken into consideration when the scores are interpreted [46,47]. We also realize that this is a rather small cross-sectional study, with participants recruited from only one city and with a higher percentage of men than in the general population [48]. The result of this study cannot be generalized to all community-dwelling older people, since they represent a unique group with many diseases. Nevertheless, the result ought to be generalizable to groups with similar conditions and living in a similar context. Another limitation of this study is the lack of data on diseases from all the ICD chapters. Data on diseases would have made it possible to identify disease clusters and use these to predict TMSAS or to describe the symptom experience of specific clusters. However, we still believe that although clustering of diseases is important and an area of interest for future studies, our results bring forward the unique perspective of an elderly population with several diseases living with a high symptom burden.

\section{Conclusion}

A large proportion of the older people with multimorbidity living in the community suffer from a high symptom burden and a high prevalence of pain. These people have an unmet need for optimized treatment focusing on the assessment, management and maintenance of the total symptom burden. People with poor vision, likelihood of depression and diseases of the digestive system are at risk of facing a higher symptom burden and might need age-specific standardized guidelines for appropriate management.

\section{Abbreviations}

BMI: Body mass index; MMSE: Mini-mental state examination; GDS-15: Geriatric depression scale; ICD: International classification of diseases.

\section{Competing interests}

The authors declare that they have no competing interests.

\section{Authors' contributions}

Study Design: AE, JE, MU, A-BW, AM, BK, TJ. Analysis: JE, KT, MU, A-BW, TJ. Manuscript preparation: JE, KT, MU, TJ. All authors performed a critical revision of the manuscript and approved the final version to be published JE, KT, $A E$, MU, A-BW, AM, BK, TJ. The manuscript has been read and approved by all authors named therein

\section{Acknowledgements}

We thank all the participants and their families included in this study We also thank the interviewers and recruiters for their assistance and support during the data collection. The first author received funding for this study from: the Faculty of Health sciences, Linkoping University; the county council of Ostergotland; the Signe and Olof Wallenius trust fund; Solstickan; and the Swedish Association of Geriatric Medicine with support from Mundipharma. The funding sources were independent and had no influence on the study.

\section{Author details}

${ }^{1}$ Department of Social and Welfare Studies, Linkoping University, Linkoping, Sweden. ${ }^{2}$ Faculty of Health, Science and Technology, Department of Health Sciences, Nursing, Karlstad University, Karlstad, Sweden. ${ }^{3}$ Department of Geriatric Medicine and Department of Social and Welfare Studies, Linkoping University, Norrkoping, Sweden. ${ }^{4}$ Department of Neurobiology, Care Sciences and Society (NVS), Division of Clinical geriatrics, Karolinska Institutet (KI), Solna, Sweden. ${ }^{5}$ Local Health Care Research and Development Unit, County Council in Ostergotland, Linkoping University, Linkoping, Sweden. ${ }^{6}$ Department of Advanced Home Care and Department of Social and Welfare Studies, Linkoping University, Norrkoping, Sweden. ${ }^{7}$ Palliative Education \& Research Centre, and Department of Social and Welfare Studies, Linkoping University, Norrkoping, Sweden. ${ }^{8}$ Department of Medicine and Health Sciences, Linkoping University, Linkoping, Sweden.

Received: 21 May 2014 Accepted: 23 December 2014

Published: 5 January 2015 


\section{References}

1. EU. The European Commission: Eurostat: Population Projections. 2011. available at: http://epp.eurostat.ec.europa.eu/statistics_explained/index.php/ Population_projections.

2. WHO. Innovative Care for Chronic Conditions: Building Blocks for Actions. http://whqlibdoc.who.int/hq/2002/WHO_NMC_CCH_02.01.pdf.

3. Salive ME. Multimorbidity in Older Adults. Epidemiol Rev. 2013;35(1):75-83.

4. Le Reste JY, Nabbe P, Manceau B, Lygidakis C, Doerr C, Lingner $\mathrm{H}$, et al. The European General Practice Research Network presents a comprehensive definition of multimorbidity in family medicine and long term care, following a systematic review of relevant literature. J Am Med Dir Assoc. 2013;14(5):319-25.

5. Marengoni A, Angleman S, Melis R, Mangialasche F, Karp A, Garmen A, et al. Aging with multimorbidity: a systematic review of the literature. Ageing Res Rev. 2011;10(4):430-9.

6. Barnett K, Mercer SW, Norbury M, Watt G, Wyke S, Guthrie B. Epidemiology of multimorbidity and implications for health care, research, and medical education: a cross-sectional study. Lancet. 2012;380(9836):37-43.

7. Walke LM, Byers AL, Gallo WT, Endrass J, Fried TR. The association of symptoms with health outcomes in chronically ill adults. J Pain Symptom Manage. 2007;33(1):58-66.

8. Drayer RA, Mulsant BH, Lenze EJ, Rollman BL, Dew MA, Kelleher K, et al. Somatic symptoms of depression in elderly patients with medical comorbidities. Int J Geriatr Psychiatry. 2005;20(10):973-82.

9. Mollaoglu M, Fertelli TK, Tuncay FO. Fatigue and disability in elderly patients with chronic obstructive pulmonary disease (COPD). Arch Gerontol Geriatr. 2011:53(2):e93-8.

10. Cuellar NG, Rogers AE, Hisghman V, Volpe SL. Assessment and treatment of sleep disorders in the older adult. Geriatr Nurs. 2007:28(4):254-64.

11. Brown ST, Kirkpatrick MK, Swanson MS, McKenzie IL. Pain experience of the elderly. Pain Manag Nurs. 2011;12(4):190-6.

12. Hareendran A, Leidy NK, Monz BU, Winnette R, Becker K, Mahler DA Proposing a standardized method for evaluating patient report of the intensity of dyspnea during exercise testing in COPD. Int J Chron Obstruct Pulmon Dis. 2012;7:345-55.

13. Lukas A, Barber JB, Johnson P, Gibson SJ. Observer-rated pain assessment instruments improve both the detection of pain and the evaluation of pain intensity in people with dementia. Eur J Pain. 2013;17(10):1558-68.

14. Cleeland CS, Reyes-Gibby CC. When is it justified to treat symptoms? Measuring symptom burden. Oncology (Williston Park). 2002;16(9):64-70.

15. Zambroski CH, Moser DK, Bhat G, Ziegler C. Impact of symptom prevalence and symptom burden on quality of life in patients with heart failure. Eur J Cardiovasc Nurs. 2005:4(3):198-206.

16. Cleeland CS. Symptom Burden: Multiple Symptoms and Their Impact as Patient-Reported Outcomes. J Natl Cancer Inst Monogr. 2007;37:16.

17. Selby D, Gill A, Chakraborty A. What is symptom burden: A qualitative exploration of patient definitions. J Palliat Care. 2012;28(2):83-9.

18. Salanitro AH, Hovater M, Hearld KR, Roth DL, Sawyer P, Locher JL, et al. Symptom burden predicts hospitalization independent of comorbidity in community-dwelling older adults. J Am Geriatr Soc. 2012;60(9):1632-7.

19. Sheppard KD, Brown CJ, Hearld KR, Roth DL, Sawyer P, Locher JL, et al. Symptom burden predicts nursing home admissions among older adults. J Pain Symptom Manage. 2013;46(4):591-7.

20. Blinderman CD, Homel P, Andrew Billings J, Tennstedt S, Portenoy RK. Symptom distress and quality of life in patients with advanced chronic obstructive pulmonary disease. J Pain Symptom Manage. 2009;38(1):115-23

21. Blinderman CD, Homel P, Billings JA, Portenoy RK, Tennstedt SL. Symptom distress and quality of life in patients with advanced congestive heart failure. J Pain Symptom Manage. 2008;35(6):594-603.

22. Gapstur RL. Symptom burden: a concept analysis and implications for oncology nurses. Oncol Nurs Forum. 2007;34(3):673-80.

23. Murtagh FE, Addington-Hall J, Edmonds P, Donohoe P, Carey I, Jenkins K, et al. Symptoms in the month before death for stage 5 chronic kidney disease patients managed without dialysis. J Pain Symptom Manage. 2010;40(3):342-52

24. Hughes LD, Hughes LD, McMurdo MET, Guthrie B. Guidelines for people not for diseases: the challenges of applying UK clinical guidelines to people with multimorbidity. Age Ageing. 2013;42(1):62-9.
25. Mazya AL, Eckerblad J, Jaarsma T, Hellström I, Krevers B, Milberg A, et al. The Ambulatory Geriatric Assessment - a Frailty Intervention Trial (AGe-FIT) - A randomised controlled trial aimed to prevent hospital readmissions and functional deterioration in high risk older adults: A study protocol. Eur Geriatr Med. 2013;4(4):242-7.

26. Portenoy RK, Thaler HT, Kornblith AB, Lepore JM, Friedlander-Klar H, Kiyasu E, et al. The Memorial Symptom Assessment Scale: an instrument for the evaluation of symptom prevalence, characteristics and distress. Eur J Cancer. 1994;30A(9):1326-36.

27. Tranmer JE, Heyland D, Dudgeon D, Groll D, Squires-Graham M, Coulson K. Measuring the symptom experience of seriously ill cance and noncancer hospitalized patients near the end of life with the Memorial Symptom Assessment Scale. J Pain Symptom Manage. 2003;25(5):420-9.

28. Pettersson G, Bertero C, Unosson M, Borjeson S. Symptom prevalence, frequency, severity, and distress during chemotherapy for patients with colorectal cancer. Support Care Cancer. 2014;22(5):1171-9.

29. Browall M, Kenne Sarenmalm E, Nasic S, Wengstrom Y, Gaston-Johansson F. Validity and reliability of the Swedish version of the Memorial Symptom Assessment Scale (MSAS): an instrument for the evaluation of symptom prevalence, characteristics, and distress. J Pain Symptom Manage. 2013;46(1):131-41.

30. Sheik J, Yesavage J. Geriatric Depression Scale (GDS): recent evidence and development of a shorter version. Clin Gerontol. 1986;5:165-72.

31. Abdulla A, Adams N, Bone M, Elliott AM, Gaffin J, Jones D, et al. Guidance on the management of pain in older people. Age Ageing. 2013:42 Suppl 1:i1-57.

32. Bergh I, Steen G, Waern M, Johansson B, Odén A, Sjöström B, et al. Pain and its relation to cognitive function and depressive symptoms: A Swedish population study of 70-year-old men and women. J Pain Symptom Manage. 2003;26(4):903-12.

33. Landi F, Onder G, Cesari M, Gambassi G, Steel K, Russo A, et al. Pain management in frail, community-living elderly patients. Arch Intern Med. 2001;161(22):2721-4.

34. Mannucci PM, Nobili A, Investigators R. Multimorbidity and polypharmacy in the elderly: Iessons from REPOSI. Intern Emerg Med. 2014;9(7):723-34.

35. Rastogi R, Meek BD. Management of chronic pain in elderly, frail patients: finding a suitable, personalized method of control. Clin Interv Aging. 2013:8:37-46.

36. Lenz ER, Pugh LC, Milligan RA, Gift A, Suppe F. The middle-range theory of unpleasant symptoms: an update. ANS Adv Nurs Sci. 1997; 19(3):14-27.

37. Landi F, Onder G, Cesari M, Russo A, Barillaro C, Bernabei R. Pain and its relation to depressive symptoms in frail older people living in the community: an observational study. J Pain Symptom Manage. 2005;29(3):255-62.

38. Marc LG, Raue PJ, Bruce ML. Screening performance of the 15-item geriatric depression scale in a diverse elderly home care population. Am J Geriatr Psychiatry. 2008;16(11):914-21.

39. Royall DR, Schillerstrom JE, Piper PK, Chiodo LK. Depression and mortality in elders referred for geriatric psychiatry consultation. J Am Med Dir Assoc. 2007;8(5):318-21.

40. Huang CQ, Dong BR, Lu ZC, Yue JR, Liu QX. Chronic diseases and risk for depression in old age: a meta-analysis of published literature. Ageing Res Rev. 2010;9(2):131-41.

41. Simren M, Svedlund J, Posserud I, Bjornsson ES, Abrahamsson H. Health-related quality of life in patients attending a gastroenterology outpatient clinic: functional disorders versus organic diseases. Clin Gastroenterol Hepatol. 2006;4(2):187-95

42. Frank L, Kleinman L, Rentz A, Ciesla G, Kim JJ, Zacker C. Health-related quality of life associated with irritable bowel syndrome: comparison with other chronic diseases. Clin Ther. 2002;24(4):675-89. discussion 674.

43. Ekdahl AW, Andersson L, Friedrichsen M. They do what they think is the best for me. Frail elderly patients' preferences for participation in their care during hospitalization. Patient Educ Couns. 2010;80(2):233-40.

44. Dodd MJ S, Facione N, Faucett J, Froelicher ES, Humphreys J, Lee K, et al. Advancing the science of symptom management. J Adv Nurs. 2001;33(5):668-76.

45. Chaudhry SI, Murphy TE, Gahbauer E, Sussman LS, Allore HG, Gill TM Restricting symptoms in the last year of life: a prospective cohort study. JAMA Intern Med. 2013;173(16):1534-40 
46. de Waal MW, van der Weele GM, van der Mast RC, Assendelft WJ, Gussekloo J. The influence of the administration method on scores of the 15-item Geriatric Depression Scale in old age. Psychiatry Res. 2012;197(3):280-4

47. Wajnberg A, Ornstein K, Zhang M, Smith KL, Soriano T. Symptom burden in chronically ill homebound individuals. J Am Geriatr Soc. 2013;61(1):126-31.

48. SCB Statistics Sweden, Population statistics. http://www.scb.se/.

doi:10.1186/1471-2318-15-1

Cite this article as: Eckerblad et al: Symptom burden in community-

dwelling older people with multimorbidity: a cross-sectional study. BMC Geriatrics 2015 15:1.

\section{Submit your next manuscript to BioMed Central and take full advantage of:}

- Convenient online submission

- Thorough peer review

- No space constraints or color figure charges

- Immediate publication on acceptance

- Inclusion in PubMed, CAS, Scopus and Google Scholar

- Research which is freely available for redistribution 